\title{
Large-arena field cage releases of a candidate classical biological control agent for spotted wing drosophila suggest low risk to non-target species
}

\author{
M. Lukas Seehausen ${ }^{1}$ (D) $\cdot$ Riccardo Valenti $^{2} \cdot$ João Fontes $^{1} \cdot$ Michela Meier $^{3} \cdot$ Cristina Marazzi $^{3} \cdot$ Dominique Mazzi $^{4}$. \\ Marc Kenis ${ }^{1}$
}

Received: 18 November 2021 / Revised: 20 January 2022 / Accepted: 15 February 2022 / Published online: 4 March 2022

(c) The Author(s) 2022

\begin{abstract}
Classical biological control, i.e., the introduction of natural enemies from an invasive pest's area of origin, has been proposed repeatedly to control the spotted wing drosophila Drosophila suzukii in the Americas and in Europe. Results from surveys in Asia and laboratory experiments suggest the parasitoid G1 Ganaspis cf. brasiliensis as a suitable biological control agent. To study the host specificity of the parasitoid under semi-field conditions, we conducted large-arena field cage releases. Parasitoids were released into cages at three dates in August 2021 in two regions of Switzerland. Released parasitoids had the choice to parasitize either $D$. suzukii larvae in fresh fruits (blueberries or elderberries) or the non-target native species $D$. melanogaster in decomposing fruits. The results were unequivocal in that apparent parasitism of $D$. suzukii larvae feeding in fresh fruits was on average $15 \%$, whereas only one parasitoid emerged from D. melanogaster feeding on decomposing fruits $(0.02 \%$ parasitism). Thus, the results support findings from previous laboratory experiments that G1 G. cf. brasiliensis is highly specific to $D$. suzukii larvae feeding in fresh fruits and parasitism of the closely related $D$. melanogaster feeding on decomposing fruits is very rare. Because in its invaded range, D. suzukii is the only Drosophila species that can attack and develop in undamaged fresh fruits, we conclude that open field releases of the parasitoid G1 G. cf. brasiliensis should not pose significant risks to non-targets.
\end{abstract}

Keywords Drosophila suzukii · G1 Ganaspis cf. brasiliensis · Importation biocontrol · Host range

\section{Key message}

- The specificity of the parasitoid G1 Ganaspis cf. brasiliensis to Drosophila suzukii was assessed in large-arena field cages

Communicated by Kent Daane.

M. Lukas Seehausen

1.seehausen@cabi.org

1 CABI, rue des Grillons 1, 2800 Delémont, Switzerland

2 Institute of Agricultural Sciences, ETH Zürich, Universitätstrasse 2, 8092 Zurich, Switzerland

3 Repubblica e Cantone Ticino, Servizio fitosanitario cantonale, Viale Stefano Franscini 17, 6501 Bellinzona, Switzerland

4 Agroscope, Research Division Plant Protection, A Ramél 18, 6593 Cadenazzo, Switzerland
- Larvae of the target species D. suzukii feeding in fresh fruits were readily parasitized

- Of 957 emerging parasitoids, only one was from larvae of the non-target species D. melanogaster feeding on decomposing fruits

- The results support findings from laboratory-based experiments and indicate the low risk for non-target effects on native Drosophila spp.

\section{Introduction}

The spotted wing drosophila Drosophila suzukii (Matsumura) (Diptera: Drosophilidae) is a frugivorous fly native to East Asia that has successfully spread in other parts of Asia as well as in the Americas, Europe, and Africa (Asplen et al. 2015; Anfora et al. 2020; Kwadha et al. 2021). As opposed to other sympatric Drosophila spp. in invaded areas, which only thrive on overripe or decomposing fruits, 
D. suzukii infests and develops in ripening fruit, which is possible due to the female's serrated ovipositor that enables this species to deposit eggs underneath the skin of undamaged fruits (Atallah et al. 2014; Karageorgi et al. 2017). Drosophila suzukii is highly polyphagous and has a broad host range that includes economically important crops (such as blackberries, blueberries, cherries, raspberries, and strawberries) as well as fruits of $>100$ non-crop and wild host plants (Poyet et al. 2015; Kenis et al. 2016). High-density populations of this invasive species cause substantial damage in soft skinned fruit crops, which leads to significant economic losses (De Ros et al. 2015; Farnsworth et al. 2017; Knapp et al. 2019).

Over the last few years, surveys were conducted in Asia by various research groups to find natural enemies of $D$. suzukii (Daane et al. 2016; Girod et al. 2018a, b; Guerrieri et al. 2016; Matsuura et al. 2018; Nomano et al. 2017; Giorgini et al. 2019). Several parasitoid species were found to attack $D$. suzukii in ripening fruits and laboratory experiments were done with the most dominant species to evaluate their suitability as biological control agents against $D$. suzukii in the invaded areas (Giorgini et al. 2019; Girod et al. 2018b; Biondi et al. 2021; Seehausen et al. 2020; Daane et al. 2021). Results of these studies revealed that Ganaspis brasiliensis (Hymenoptera: Figitidae) is the most specific parasitoid of $D$. suzukii, however, varying host specificities have been found between different G. brasiliensis populations.

Asian populations of this species were divided into 4-5 genetic groups, now called G1-G5 G. cf. brasiliensis (Nomano et al. 2017; Seehausen et al. 2020). And also a study analyzing the expressed proteins of $G$. brasiliensis from different sites in Asia using MALDI-TOF MS found significant differences in spectra, dividing the species into two different groups (Reeve and Seehausen 2019). Further studies suggested that $G$. brasiliensis is a species complex composed of at least two cryptic species with differing host specificities. Under laboratory conditions, individuals from the G3-4 group were shown to attack various Drosophila spp. larvae independently of their food source, while G1 individuals almost exclusively parasitized Drosophila spp. larvae feeding on ripening fruits (Seehausen et al. 2020). Because in the invaded areas, D. suzukii is the only drosophilid that can lay eggs in fresh fruits, the ecological host range of G1 G. cf. brasiliensis is very likely to be restricted to this species.

Based on the results of the laboratory studies, permits to release G1 G. cf. brasiliensis as a classical biological control agent against $D$. suzukii are now being requested in various countries. In Switzerland, following a discussion between the authors of this article and Swiss authorities from the Federal Office of the Environment, an application for largearena field cage releases has been submitted under the
Ordinance on the Handling of Organisms in the Environment (Release Ordinance) to study the host and habitat specificity of G1 G. cf. brasiliensis under semi-field conditions and further support studies on the host specificity of this species for releases in Europe. Experimental field cage releases were granted by the Swiss government in June 2021.

Large-arena choice tests and field tests have been suggested for the host range assessment of potential biological control agents (van Lenteren et al. 2006). Host specificity tests under laboratory conditions are often done in relatively small containers, with only parts of the host plants, and homogeneous environmental conditions (e.g. constant temperature, humidity, and light). Choice tests in large cages may yield more accurate host range estimates because they allow for a more realistic host finding and patch exploitation behavior by the biological control agent. If the large-arena choice tests are done in field cages, environmental conditions that are closer to field conditions (here referred to as semi-field conditions) may add even more realism. Nevertheless, other aspects of realism are missing from large-arena field cages (e.g. due to the restriction of flight by the nets or the exposure of hosts only during limited time periods) and thus, host range estimates from such studies may still differ from the ecological host range of a biological control agent after open field releases. However, results from laboratory host specificity studies are generally conservative and largearena tests with entire host plants may help to reduce the hazard of overestimating a biological control agent's host range (van Lenteren et al. 2006).

The goals of this study were (1) to test releases of a parasitoid into large-arena field cages as a method for corroborating its host specificity under semi-field conditions, and (2) to verify G1 G. cf. brasiliensis' specificity to Drosophila spp. in fresh fruits under more natural conditions. Based on results under laboratory conditions, it was hypothesized that also in large-arena field cages, G1 G. cf. brasiliensis readily parasitizes $D$. suzukii larvae in undamaged ripening or ripe fruits, whereas parasitism of the non-target species $D$. melanogaster in decomposing fruits is rare or absent.

\section{Materials and methods}

The cage releases were conducted in two sites in Switzerland, which correspond geographically to southern and northern extremes of the country and exhibit different climatic conditions, under which $D$. suzukii has been reported to cause damage to fruits (Kenis et al. 2016; Knapp et al. 2019). South of the Alps, the site was situated in Cadenazzo (46.1600, 8.9342; $200 \mathrm{~m}$ a.s.l.), canton of Ticino, on the property of Agroscope, the Swiss centre of excellence for agricultural research, which is affiliated with the Federal Office for Agriculture. The site is 
generally sheltered from cold northern winds due to its location south of the Alps and the nearby Lake Maggiore provides it with a relatively mild climate in winter. The site north of the Alps was situated in Delémont (47.3733, $7.3265 ; 540 \mathrm{~m}$ a.s.1.), canton of Jura, on the property of the Centre for Agriculture and Biosciences International (CABI). This site is on the southern slope of the Delémont Valley, a wide depression in the Jura Mountains, which is dominated by weather fronts reaching Switzerland from the west, resulting in frequent precipitation during the year and cold air fronts in winter.

On each site, three $2 \times 2 \times 1.6 \mathrm{~m}$ (length $\times$ width $\times$ height) field cages were built with metal frames that were buried $40 \mathrm{~cm}$ into the soil and covered with a fine mesh $(70 \times 22$ per square inch) polyester netting (Brettschneider Fernreisebedarf $\mathrm{GmbH}$ ) with a zipper on one side as a door. Inside the cages, the upper soil layer was replaced with sand to improve safety by decreasing the likelihood of the insects' escape through the soil. All three cages and a fourth metal frame building a safety corridor (also called airlock) in front of the three cages were covered with an additional $5 \times 4 \times 2 \mathrm{~m}$ fine mesh netting of the same type as described above, forming a second layer for more stability and increased safety. A zipper served as entrance door between the outside and the safety corridor. The lower ends of both net layers were wrapped together around metal rods and then buried approximately $10 \mathrm{~cm}$ into the ground to fasten the cages in place. Semipermeable polyester tarps and additional covers made of wooden laths were installed on top of the cage structure and anchored to the ground to shade the cages and as weather protection (e.g., against hail). Five double-sided yellow sticky traps were placed within the safety corridor and ten one-sided yellow sticky traps outside and facing the main cage to trap any parasitoids, in the unlikely event of escape (Fig. 1a).

The starting colonies of D. suzukii, D. melanogaster and G1 $G$. cf. brasiliensis were collected and successively reared as described by Seehausen et al. (2020). All G1 G. cf. brasiliensis used for the experiments described here were collected near Tokyo, Japan, and were reared in the quarantine laboratory of CABI in Delémont, Switzerland. Specimen of the parasitoid rearing colony were collected periodically and DNA analyses ensured that it contained no other than G1 G. cf. brasiliensis (Seehausen et al. 2020). Mated parasitoid females were stockpiled for up to three weeks before the cage releases at $20{ }^{\circ} \mathrm{C}$ in ventilated vials and provided with honey water on foam plugs renewed every 2-3 days.

Approximately $36-24 \mathrm{~h}$ before the field cage releases, plants with ripe (but not overripe) fruits were exposed to $D$. suzukii in cages for oviposition. At the same time, six Petri dishes with about three tablespoons of decomposing fruits were exposed to several hundred D. melanogaster in a cage placed at room temperature. To decompose fruits, they were cut and exposed to room temperature in a plastic container for at least two weeks until growth of mold was visible.

The morning of the field cage release, the plants and the dishes with decomposing berries were removed from the oviposition cages. The plastic vials containing the parasitoids were put in a zip-lock bag and placed into a cooling box for the transportation to the field cages. To avoid entering the cages, two metal planks were placed in each of the three cages, which could be easily slid in and out from the zipper door. On each plank, one plant carrying berries infested with $D$. suzukii and one Petri dish containing decomposing berries infested with $D$. melanogaster were placed (Fig. 1a). The dishes with decomposing fruits were placed on upturned ceramic flowerpots in ant-proof containers, which consisted of a plastic dish that was filled with soapy water and a roof to protect the dishes from rainwater (Fig. 1b). As a food source for the parasitoids, two vials with honey water on foam plugs were attached to bamboo sticks and placed in each cage. One temperature data logger with a 30 min measurement frequency was placed inside one of the cages in each site.

Before opening the field cages to release the parasitoids, a white coverall was put on in the safety corridor. The parasitoids were released from the plastic containers into the field cages by opening only the upper part of the zipper door of the field cage, which was placed in the middle between the two metal planks containing the host plant material (Fig. 1a), holding the container into the cage, and opening the foam plug on the top of the container to let the parasitoids fly out on their own. The few females that remained in the container after about one minute were removed by holding the container upside-down and gently shaking it. In both sites, releases of the parasitoids were done in each of the three cages on three dates in August 2021, with 10-20 released G1 G. cf. brasiliensis females, and different host plant species (Table 1). The northern highbush blueberry (Vaccinium corymbosum) plants were received from Agroscope in Conthey (varieties Draper and Duke) and from the tree nursery 'von Dach AG' in Lyss, Switzerland (variety Goldtraube). All blueberry plants carried between 10 and 50 ripe or ripening blueberries. Decomposing fruits were commercial organic blueberries from the local grocery store. European black elder (Sambucus nigra) branches were collected on the forest edges around the site in Delémont and contained at least one cluster of 30-100 ripe berries. Three branches were bundled together and placed in a container with water to prevent them from drying out. Decomposing elderberries were from the same source.

Wearing a white coverall, the plants and decomposing berries were taken out of the cages after $72 \mathrm{~h}$ of exposure by sliding the metal planks to the entrance. The berries were collected from the plants into ventilated plastic boxes and placed into a zip-lock bag. The dishes containing 
Fig. 1 a Plan of the setup for the release of the parasitoid G1 Ganaspis cf. brasiliensis into large-arena field cages. The $2 \times 2 \mathrm{~m}$ cages (grey squares) were placed inside a bigger cage, creating a safety corridor. Within each cage were metal planks (dark grey rectangles) on which berry plants infested with Drosophila suzukii (green flower symbol) and petri dishes with decomposing berries infested with Drosophila melanogaster (white circles) were placed. Within the safety corridor and around the cages, yellow sticky traps (yellow rectangles) were installed to trap any escaping parasitoids. b Model drawing of the ant-proof containers used in the field cage releases to expose decomposing fruits to the parasitoids. Dishes with the decomposing fruits were placed on upturned ceramic flowerpots within a plastic dish filled with soapy water. A roof was fixed over the installation to protect the dishes from rainwater

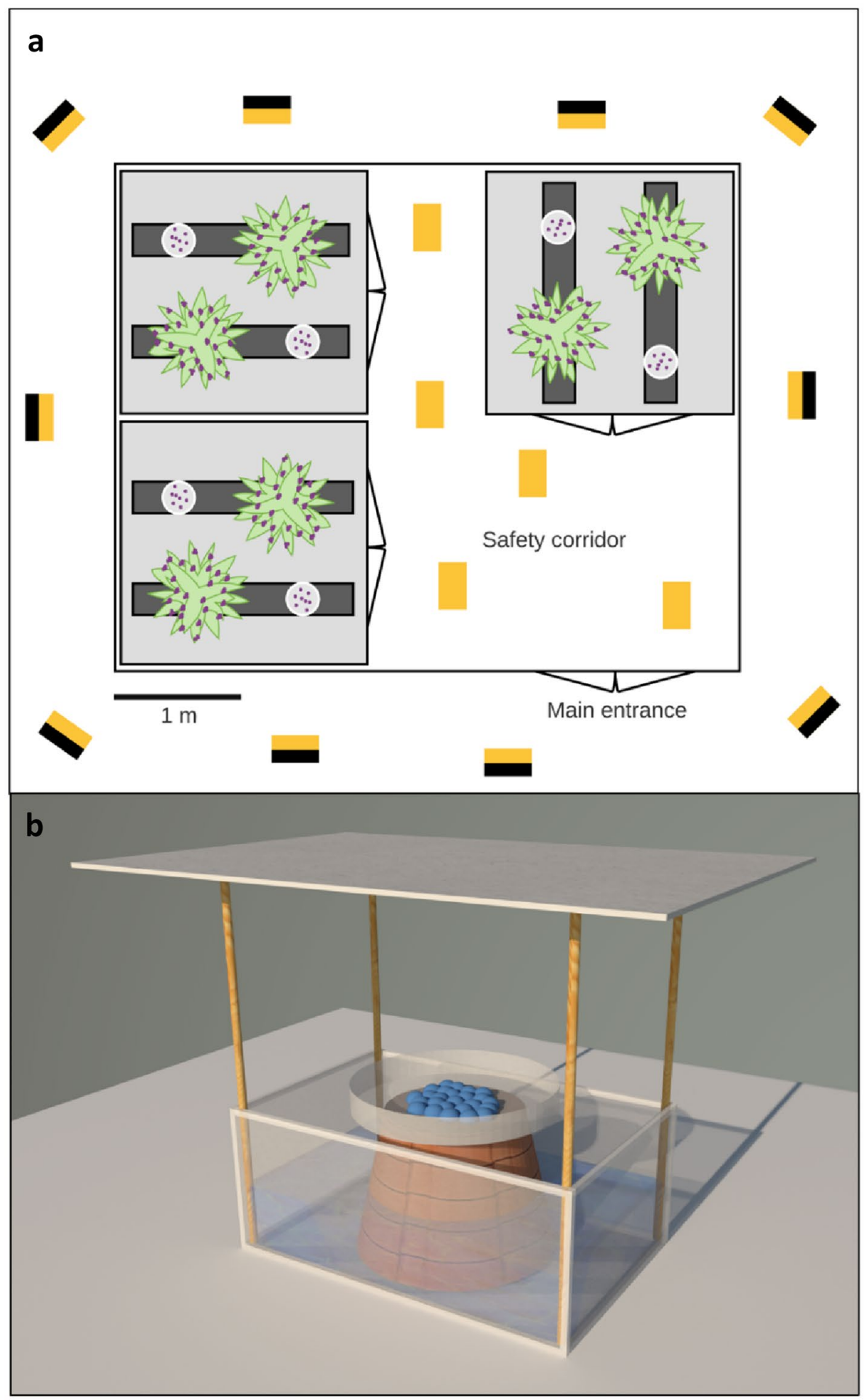

decomposing fruits were closed with a ventilated lid and placed into separate zip-lock bags. The plants from which the fruits were removed were then gently shaken (so that parasitoids possibly still on them fly off), cut into little pieces, and placed with the pot and soil into a plastic bag. The plastic bag was closed and placed into a second bag, and then frozen at $-20^{\circ} \mathrm{C}$ for at least $72 \mathrm{~h}$ to kill any parasitoids that may have remained on the plant material. Before leaving the safety corridor, the white coverall was taken off and stored in a plastic box left in the safety corridor to prevent parasitoids from exiting the cages hidden on clothing. The container with collected berries in zip-locks was stored in a cooling box and transported to CABI's quarantine facility in Delémont. 
Table 1 Release dates, host plants, and number of G1 Ganaspis cf. brasiliensis females released into field cages in Cadenazzo (TI) and Delémont (JU), Switzerland

\begin{tabular}{llll}
\hline Site & Release date & Host plant & $\begin{array}{l}\text { Number of } \\
\text { parasitoids }\end{array}$ \\
\hline Cadenazzo (TI) & $06 / 08$ & Blueberry, var. 'Duke' & 10 \\
& $13 / 08$ & Blueberry, var.'Goldtraube' & 20 \\
& $31 / 08$ & European black elder & 20 \\
Delémont (JU) & $10 / 08$ & Blueberry, var. 'Draper' & 10 \\
& $20 / 08$ & Blueberry, var. 'Goldtraube' & 20 \\
& $24 / 08$ & European black elder & 20 \\
\hline
\end{tabular}

In the quarantine laboratory, the berries were placed inside labeled rearing vials and kept at room temperature, $60 \%$ relative humidity, and a $16 \mathrm{~h}$ light to $8 \mathrm{~h}$ dark diel period. The emerging flies and parasitoids were removed from the vials every $2-3 \mathrm{~d}$ and placed into alcohol. Only flies emerging up to 21 days and parasitoids emerging up to 42 days after incubation were counted per cage and berry treatment (fresh or decomposing), to avoid including individuals from a second generation.

\section{Data analysis}

Apparent parasitism (proportion of parasitoid offspring among the total number of emerging insects) was analyzed with a logistic regression with quasibinomial distribution using the glm function of the stats package in $\mathrm{R}$ ( $\mathrm{R}$ Core Team 2021). A quasibinomial distribution was used because residuals were overdispersed, as determined by a Pearson chi-square test. Apparent parasitism was taken as independent variable and the three factors (1) host species (D. suzukii or D. melanogaster) in their respective plant material (fresh or decomposing fruits), (2) mean air temperature $\left({ }^{\circ} \mathrm{C}\right)$ in the cages during the release periods, and (3) the number of host flies per released parasitoid female, as well as all interactions of these three factors, were taken as dependent variables. Post-hoc tests with Tukey adjustments were used to compare means of significant effects.

\section{Results}

Mean temperatures during the three days of releases were 23.3, 20.1, $16.9{ }^{\circ} \mathrm{C}$, and 20.9, 24.9, $19.7^{\circ} \mathrm{C}$ in Delémont and Cadenazzo, respectively. The number of Drosophila flies emerging from the exposed berries was quite variable (see Supplementary Information). On average ( \pm standard error), more flies emerged from fresh fruits, when compared to decomposing ones, in both Cadenazzo (251 \pm 69 vs. $132 \pm 30)$ and Delémont $(589 \pm 91$ vs. $161 \pm 60)$. Parasitism of fly larvae in fruits by G1 G. cf. brasiliensis occurred in all cages, temporal repetitions, and sites. However, out of
2632 flies, only one individual of D. melanogaster feeding on decomposing fruits was parasitized $(0.04 \%)$, as opposed to 956 out of 8522 flies (11.22\%) for D. suzukii in fresh fruits. The one parasitoid emerging from $D$. melanogaster was a male $G$. cf. brasiliensis, as determined morphologically using the characteristics described by Buffington and Forshage (2016).

The statistical analysis showed that two of the three single factors (host species/fruit status and host density) but none of the interactions significantly influenced apparent parasitism of Drosophila spp. in the field cages (Table 2). Mean ( \pm standard error) apparent parasitism was significantly higher for $D$. suzukii larvae feeding on fresh fruits $(15.4 \pm 3.5 \%)$, when compared to D. melanogaster feeding on decomposing ones $(0.02 \pm 0.02)$ (Fig. 2a). Taking sample sizes into account, differences in model predictions for the probability of parasitism of the two fly species are even clearer: $17.9 \pm 2.7 \%$ for $D$. suzukii in fresh fruit and $<0.0001 \%$ for D. melanogaster in decomposing fruits. Additionally, apparent parasitism significantly decreased with the number of host flies in each cage per released parasitoid female (Table 2). Given that parasitism of D. melanogaster in decomposing fruits was mainly zero, the slope of this relationship is relatively flat when including non-target hosts, while it is quite steep when excluding them (Fig. 2b).

Table 2 Analysis of deviance table for the results of the logistic regression analyzing the effect of host species (Drosophila suzukii in fresh fruit and D. melanogaster in decomposing fruits), mean air temperature during the release periods, and the number of host flies per released parasitoid female on apparent parasitism of Drosophila larvae by the parasitoid G1 Ganaspis cf. brasiliensis in large-arena field cages

\begin{tabular}{lrrr}
\hline Variable & $\chi^{2}$ value & \multicolumn{1}{c}{ df } & \multicolumn{1}{c}{$P$ value } \\
\hline Host species & 54.90 & 1,27 & $<0.0001$ \\
Mean air temperature & 0.02 & 1,27 & 0.8951 \\
Host density & 23.22 & 1,27 & $<0.0001$ \\
Species $\times$ temperature & 0.27 & 1,27 & 0.6010 \\
Species $\times$ density & 0.14 & 1,27 & 0.7090 \\
Temperature $\times$ density & 1.31 & 1,27 & 0.2519 \\
Species $\times$ temperature $\times$ density & $<0.01$ & 1,27 & 1.0000 \\
\hline
\end{tabular}




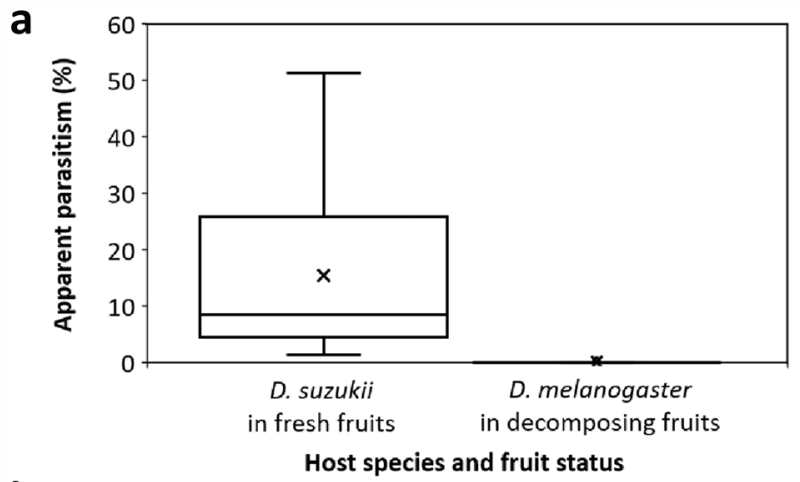

b

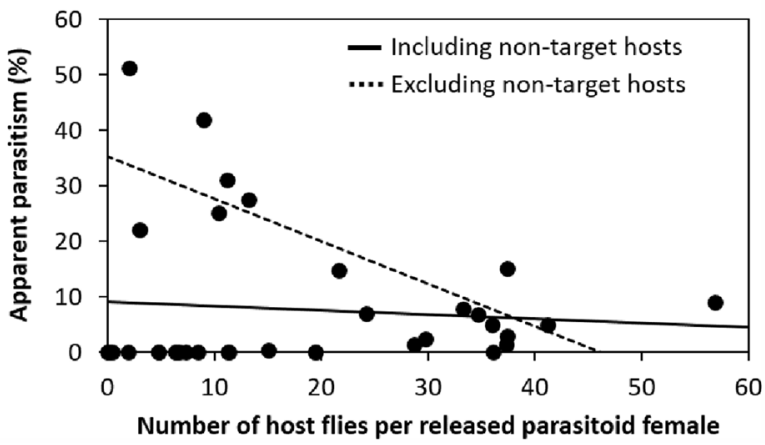

Fig. 2 Results of the releases of G1 Ganaspis cf. brasiliensis into large-arena field cages in terms of a percentage apparent parasitism of Drosophila suzukii in fresh fruits and D. melanogaster in decomposing fruits and $\mathbf{b}$ the relationship between the number of host flies per released parasitoid female and percentage apparent parasitism (solid line) including D. melanogaster as non-target species and (dashed line) excluding the non-target species (D. suzukii alone)

Mean air temperature in the cages had no significant influence on apparent parasitism (Table 2).

\section{Discussion}

The results of the releases of G1 G. cf. brasiliensis in largearena field cages support earlier evidence that the parasitoid is highly specific to $D$. suzukii larvae feeding in fresh fruits. Parasitism of the closely related frugivorous non-target species $D$. melanogaster feeding on decomposing fruits occurs, but is very rare. Only a single parasitoid emerged from $D$. melanogaster. This confirms our hypothesis and supports the results of previous laboratory choice and no-choice experiments performed in relatively small containers (Giorgini et al. 2019; Girod et al. 2018b; Biondi et al. 2021; Seehausen et al. 2020; Daane et al. 2021).

Our study also supports the finding that G1 G. cf. brasiliensis is a suitable biological control agent for $D$. suzukii. In its area of invasion, D. suzukii is the only drosophilid that is able to attack undamaged fresh fruits, all other native species of frugivorous drosophila can only oviposit on damaged and decomposing fruits. Therefore, the high specificity of
G1 G. cf. brasiliensis to larvae in fresh fruits translates to a high specificity of this parasitoid to $D$. suzukii in its area of invasion. In Asia, other drosophila species such as $D$. pulchrella and $D$. subpulchrella are known to also attack fresh fruits and may therefore be attacked by this parasitoid (Girod et al. 2018a). The physiological host range of G1 $G$. cf. brasiliensis clearly includes non-target species, such as the taxonomically closely related $D$. simulans and $D$. melanogaster (Seehausen et al. 2020). However, under natural conditions in Asia, the parasitoid has so far only been reared from $D$. suzukii attacking fresh fruits, and never from other media such as fruit baits (Kasuya et al. 2013; Daane et al. 2016; Girod et al. 2018a; Giorgini et al. 2019) or other drosophila species (Nomano et al. 2017). Our results show that under semi-field conditions, attack of $D$. melanogaster as a non-target species occurs, but is very rare. But only one nontarget species was tested in our field cage releases, results may differ for other species. The risk of released parasitoids to also occasionally attack and kill native Drosophila species cannot be excluded, especially those that can be found in rotten or even injured fruits, such as D. melanogaster and D. simulans. But given the results of laboratory experiments (Giorgini et al. 2019; Girod et al. 2018b; Biondi et al. 2021; Seehausen et al. 2020; Daane et al. 2021) and our field cage releases, parasitism of non-target species can be expected to be negligible and unlikely to have any significant ecological impact.

While D. melanogaster is unable to pierce through the skin of undamaged ripening and ripe fruits and is therefore usually absent from them, D. suzukii can be found in both fresh and decomposing fruits (Karageorgi et al. 2017). Here, we did not expose D. suzukii in decomposing fruits and $D$. melanogaster in damaged fresh fruits (but see Seehausen et al. 2020). However, it is possible that some adult flies were present in the field cages and oviposited in any of the substrates during the exposure period. The co-occurrence of both species in the same substrates, as occurs under natural conditions, may influence the risk of non-target attacks. Thus, a future study may also expose target and non-target species in the same substrate and separate host pupae from the samples based on their morphology (e.g. as described by Abram et al. 2022) to confirm host-parasitoid associations.

Apparent parasitism of host flies significantly decreased with increasing host densities, which was driven by parasitism of the target host $D$. suzukii, as parasitism of the nontarget host was zero in all but one case. Our estimates of host density (number of flies reared from the fruits divided by the number of released parasitoids) may be relatively imprecise, because (1) a certain number of hosts may have died during the laboratory rearing, (2) some parasitoids may have remained alive in the cages between the release periods, and (3) differential mortality of host species in different fruits (i.e., blueberries and elderberries). At least under 
laboratory conditions, attack of $D$. suzukii by $G$. cf. brasiliensis is known to be positively density-dependent (Wang et al. 2020a). But female parasitoids produce a mean maximum of eight offspring per day (Wang et al. 2018), and may thus become egg limited at high densities. Under natural conditions in Asia (China and Japan), apparent parasitism of $D$. suzukii by $G$. cf. brasiliensis has been found to also be rather variable $(<1-76 \%)$, with a mean $( \pm$ standard error) percentage of $11 \%$ (Girod et al. 2018a). But these numbers likely underestimate parasitism rates in the field because, to avoid other drosophilids, Girod et al. (2018a) collected mostly undamaged fruits, i.e., including many fruits with D. suzukii eggs or hatching larvae before being parasitized.

Problems were experienced during the experiments with low survival of D. melanogaster larvae in decomposing fruits, especially with elderberries, which led to fewer emerging adult flies, when compared to fresh fruits. This may have been due to toxic products from fermenting fruits and/or the drying of the substrate during the release period. We cannot exclude that at least part of the high mortality of $D$. melanogaster was due to non-reproductive mortality of the fly inflicted by the parasitoid; i.e., the parasitoid may have found, attacked, and killed D. melanogaster in the trials but did not successfully develop (with one exception). However, the lower numbers of flies are considered by our statistical analysis, which calculates probabilities of parasitism based on the total number of individual parasitoids and flies, and therefore, do not undermine our conclusion that parasitism of D. melanogaster feeding on decomposing fruits only seldom occurs.

In most countries, very detailed information about many aspects of a potential biological control agent and its target pest is needed to apply for the release of beneficial insects as biological control agents against invasive species. Independent research groups conduct experiments over several years to gather information assessing possible non-target impacts. Since its confirmation in the late 2000s as an invasive species in Europe and North America, research about the classical biological control of $D$. suzukii has well advanced (reviewed by Wang et al. 2020b). With the first releases of G. cf. brasiliensis in Italy in 2021, a recent acceptance of the application for releases of the same parasitoid in the US, and the submission of an application in Switzerland in February 2022, the research starts to be implemented into practice. In this context, our large-arena field cage releases support findings of laboratory-based studies that showed a high specificity of the parasitoid G1 G. cf. brasiliensis to $D$. suzukii larvae feeding in fresh fruits, when compared to non-target species feeding on decomposing fruits. The low occurrence of non-target attacks in choice tests under laboratory conditions and in the here conducted large-arena field cage experiment suggests that populations of non-target species would not be impacted by the parasitoid and that the possible non-target impacts are a low and acceptable risk for the control of the destructive invasive spotted wing drosophila.

\section{Author contributions}

MLS and MK conceived and designed the experiment. MLS, MK, and CM acquired funding. JF, RV, MLS, CM, MM, and DM constructed the field cages. JF, RV, MLS, and DM conducted the experiment. JF curated the data. MLS and RV analyzed the data and wrote the first draft of the manuscript. All authors discussed the results and edited the manuscript.

Supplementary Information The online version contains supplementary material available at https://doi.org/10.1007/s10340-022-01487-3.

Acknowledgements We thank the Phytosanitary Service of Ticino for submitting the application for the field cage releases and Bastien Christ (Agroscope) for providing blueberry plants for the experiments.

Funding The research leading to these results received funding from the Swiss Federal Office for the Environment, the Swiss Federal Office for Agriculture, and the Horizon 2020 Program for Research \& Innovation under grant agreement no. 771271 (HOMED). MLS and MK were supported by CABI with core financial support from its member countries (see https://www.cabi.org/about-cabi/who-we-work-with/ key-donors/).

\section{Declarations}

Conflict of interest The authors have no competing interests to declare that are relevant to the content of this article.

Ethical approval All applicable international, national, and/or institutional guidelines for the care and use of animals were followed. This article does not contain any studies with human participants performed by any of the authors.

Open Access This article is licensed under a Creative Commons Attribution 4.0 International License, which permits use, sharing, adaptation, distribution and reproduction in any medium or format, as long as you give appropriate credit to the original author(s) and the source, provide a link to the Creative Commons licence, and indicate if changes were made. The images or other third party material in this article are included in the article's Creative Commons licence, unless indicated otherwise in a credit line to the material. If material is not included in the article's Creative Commons licence and your intended use is not permitted by statutory regulation or exceeds the permitted use, you will need to obtain permission directly from the copyright holder. To view a copy of this licence, visit http://creativecommons.org/licenses/by/4.0/.

\section{References}

Abram PK, Wang X, Hueppelsheuser T, Franklin MT, Daane KM, Lee JC, Lue CH, Girod P, Carrillo J, Wong WH, Kula RR (2022) A coordinated sampling and identification methodology for larval 
parasitoids of spotted-wing drosophila. J Econ Entomol toab237. https://doi.org/10.1093/jee/toab237

Anfora G, Bouharoud R, Chebli B (2020) First report of Drosophila suzukii (Diptera: Drosophiladae) in North Africa. Moroc J Agric Sci 1:277-279

Asplen MK, Anfora G, Biondi A, Choi DS, Chu D, Daane KM, Gibert P, Gutierrez AP, Hoelmer KA, Hutchison WD, Isaacs R (2015) Invasion biology of spotted wing Drosophila (Drosophila suzukii): a global perspective and future priorities. J Pest Sci 88:469-494. https://doi.org/10.1007/s10340-015-0681-z

Atallah J, Teixeira L, Salazar R, Zaragoza G, Kopp A (2014) The making of a pest: the evolution of a fruit-penetrating ovipositor in Drosophila suzukii and related species. Proc R Soc B 281:20132840. https://doi.org/10.1098/rspb.2013.2840

Biondi A, Wang X, Daane KM (2021) Host preference of three Asian larval parasitoids to closely related Drosophila species: implications for biological control of Drosophila suzukii. J Pest Sci 94:273-283. https://doi.org/10.1007/s10340-020-01272-0

Buffington ML, Forshage M (2016) Redescription of Ganaspis brasiliensis (Ihering, 1905), new combination, (Hymenoptera: Figitidae) a natural enemy of the invasive Drosophila suzukii (Matsumura, 1931) (Diptera: Drosophilidae). Proc Entomol Soc Wash 118:1-13. https://doi.org/10.4289/0013-8797.118.1.1

Daane KM, Wang XG, Biondi A, Miller B, Miller JC, Riedl H, Shearer PW, Guerrieri E, Giorgini M, Buffington M, van Achterberg K (2016) First exploration of parasitoids of Drosophila suzukii in South Korea as potential classical biological agents. J Pest Sci 8:823-835. https://doi.org/10.1007/s10340-016-0740-0

Daane KM, Wang X, Hogg BN, Biondi A (2021) Potential host ranges of three Asian larval parasitoids of Drosophila suzukii. J Pest Sci 94:1171-1182. https://doi.org/10.1007/s10340-021-01368-1

De Ros G, Conci S, Pantezzi T, Savini G (2015) The economic impact of invasive pest Drosophila suzukii on berry production in the Province of Trento, Italy. J Berry Res 5:89-96. https://doi.org/ 10.3233/JBR-150092

Farnsworth D, Hamby KA, Bolda M, Goodhue RE, Williams JC, Zalom FG (2017) Economic analysis of revenue losses and control costs associated with the spotted wing drosophila, Drosophila suzukii (Matsumura), in the California raspberry industry. Pest Manag Sci 73:1083-1090. https://doi.org/10.1002/ps.4497

Giorgini M, Wang X-G, Wang Y, Chen F-S, Hougardy E, Zhang H-M, Chen Z-Q, Chen H-Y, Liu C-X, Cascone P, Formisano G, Carvalho GA, Biondi A, Buffington M, Daane KM, Hoelmer KA, Guerrieri E (2019) Exploration for native parasitoids of Drosophila suzukii in China reveals a diversity of parasitoid species and narrow host range of the dominant parasitoid. J Pest Sci 92:509-522. https://doi.org/10.1007/s10340-018-01068-3

Girod P, Borowiec N, Buffington M, Chen G, Fang Y, Kimura MT, Peris-Felipo FJ, Ris N, Wu H, Xiao C, Zhang J (2018a) The parasitoid complex of D. suzukii and other fruit feeding Drosophila species in Asia. Sci Rep 8:1-8. https://doi.org/10.1038/ s41598-018-29555-8

Girod P, Lierhmann O, Urvois T, Turlings TCJ, Kenis M, Haye T (2018b) Host specificity of Asian parasitoids for potential classical biological control of Drosophila suzukii. J Pest Sci 91:1241-1250. https://doi.org/10.1007/s10340-018-1003-Z

Guerrieri E, Giorgini M, Cascone P, Carpenito S, Van Achterberg C (2016) Species diversity in the parasitoid genus Asobara (Hymenoptera: Braconidae) from the native area of the fruit fly pest Drosophila suzukii (Diptera: Drosophilidae). PLoS ONE 11:e0147382. https://doi.org/10.1371/journal.pone.0147382

Karageorgi M, Brńcker LB, Lebreton S, Minervino C, Cavey M, Siju KP, Kadow ICG, Gompel N, Prud'homme B (2017) Evolution of multiple sensory systems drives novel egg-laying behavior in the fruit pest Drosophila suzukii. Curr Biol 27:847-853. https://doi. org/10.1016/j.cub.2017.01.055
Kasuya N, Mitsui H, Ideo S, Watada M, Kimura MT (2013) Ecological, morphological and molecular studies on Ganaspis individuals (Hymenoptera: Figitidae) attacking Drosophila suzukii (Diptera: Drosophilidae). Appl Entomol Zool 48:87-92. https://doi.org/10. 1007/s13355-012-0156-0

Kenis M, Tonina L, Eschen R, van der Sluis B, Sancassani M, Mori $\mathrm{N}$, Haye T, Helsen H (2016) Non-crop plants used as hosts by Drosophila suzukii in Europe. J Pest Sci 89:735-748. https://doi. org/10.1007/s 10340-016-0755-6

Knapp L, Mazzi D, Finger R (2019) Management strategies against Drosophila suzukii: insights into Swiss grape growers choices. Pest Manag Sci 75:2820-2829. https://doi.org/10.1002/ps.5397

Kwadha CA, Okwaro LA, Kleman I, Rehermann G, Revadi S, Ndlela S, Khamis FM, Nderitu PW, Kasina M, George MK, Kithusi GG, Mohamed SA, Lattorff HMG, Becher PG (2021) Detection of the spotted wing drosophila, Drosophila suzukii, in continental subSaharan Africa. J Pest Sci 94:251-259. https://doi.org/10.1007/ s10340-021-01330-1

Matsuura A, Mitsui H, Kimura MT (2018) A preliminary study on distributions and oviposition sites of Drosophila suzukii (Diptera: Drosophilidae) and its parasitoids on wild cherry tree in Tokyo, central Japan. Appl Entomol Zool 53:47-53. https://doi.org/10. 1007/s13355-017-0527-7

Nomano FY, Kasuya N, Matsuura A, Suwito A, Mitsui H, Buffington ML, Kimura MT (2017) Genetic differentiation of Ganaspis brasiliensis (Hymenoptera: Figitidae) from East and Southeast Asia. Appl Entomol Zool 52:429-437. https://doi.org/10.1007/ s13355-017-0493-0

Poyet M, Le Roux V, Gibert P, Meirland A, Prevost G, Eslin P, Chabrerie $O$ (2015) The wide potential trophic niche of the Asiatic fruit fly Drosophila suzukii: the key of its invasion success in temperate Europe? PLoS ONE 10:e0142785. https://doi.org/10.1371/journ al.pone. 0142785

R Core Team (2021) R: a language and environment for statistical computing. R Foundation for Statistical Computing, Vienna, Austria. https://www.R-project.org/

Reeve MA, Seehausen ML (2019) Discrimination between Asian populations of the parasitoid wasp Ganaspis $\mathrm{cf}$. brasiliensis using a simple MALDI-TOF MS-based method for use with insects. Biol Methods Protoc 4:bpz002. https://doi.org/10.1093/biomethods/ bpz002

Seehausen ML, Ris N, Driss L, Racca A, Girod P, Warot S, Borowiec N, Toševski I, Kenis M (2020) Evidence for a cryptic parasitoid species reveals its suitability as a biological control agent. Sci Rep 10:1-12. https://doi.org/10.1038/s41598-020-76180-5

van Lenteren JC, Cock MJ, Hoffmeister TS, Sands DP (2006) Host specificity in arthropod biological control, methods for testing and interpretation of the data. In: Bigler F, Babendreier D, Kuhlmann U (eds) Environmental impact of invertebrates for biological control of arthropods. Methods and risk assessment. CABI Publishing, Wallingford, pp 38-63. https://doi.org/10.1079/97808 51990583.0038

Wang XG, Nance AH, Jones JM, Hoelmer KA, Daane KM (2018) Aspects of the biology and reproductive strategy of two Asian larval parasitoids evaluated for classical biological control of Drosophila suzukii. Biol Control 121:58-65. https://doi.org/10. 1016/j.biocontrol.2018.02.010

Wang X, Biondi A, Daane KM (2020a) Functional responses of three candidate Asian larval parasitoids evaluated for classical biological control of Drosophila suzukii (Diptera: Drosophilidae). J Econ Entomol 113:73-80. https://doi.org/10.1093/jee/toz265

Wang X, Lee JC, Daane KM, Buffington ML, Hoelmer KA (2020b) Biological control of Drosophila suzukii. CAB Rev 15:1-19. https://doi.org/10.1079/PAVSNNR202015054 
Publisher's Note Springer Nature remains neutral with regard to jurisdictional claims in published maps and institutional affiliations. 